\title{
Using diaries to collect data
}

\section{DEBORAH GOODALL}

\section{Introduction}

During 1993-1995 CERLIM carried out research on franchised higher education courses. The aim of the project was to provide a clear understanding of how library services are being and could be provided to support franchised courses, how students meet their library and information needs, and what might improve the nature and level of library support. The core of the project was an investigation of the actual experience of students on franchised courses in relation to the provision and availability of library resources. A sample of 45 off-campus students together with a control sample of 46 in-house students was selected from a range of five subject disciplines: Business, Engineering, English, Health and Leisure. Participating students kept diaries to record their everyday experiences of using libraries as they completed pieces of assessed work and were engaged in follow-up focus group discussions with the researcher. To overcome possible poor response rates (or rather, high drop-out rates) the students who participated in the study were paid $£ 25$ at the end of the academic year. This article describes the use of diaries as a research tool in this context.

\section{Using diaries ${ }^{(1)}$ and focus groups to investigate library use}

The specific aims of the diary work were to document the actual experience of students in relation to the provision and availability of library resources and to consider whether franchised students are disadvantaged compared to in-house colleagues. Little work appears to have been done in this area and the only relevant reference found during the literature search related to a comparison of references cited by on-campus and off-campus graduate Library Science students at Emporia State University. The question that lay behind this formative study was: will off-campus students be hampered in producing scholarly work because they have fewer research resources at hand than on-campus students, or will their work reflect the same quality of research to be found in that of on-campus students? Much of the paper is concerned with establishing a methodology for carrying out such comparisons and the findings are based only on the results from volunteer students. The researchers concluded that "off-campus students appear not to be at a disadvantage in gaining access to scholarly work. If, in fact, there is a disadvantage, then the students at the nonmetropolitan distance site were able to compensate by overcoming the obstacles they met and indeed equalled or exceeded students in other sites."(2)

In this project, to provide a clear understanding of how students satisfy their information needs and to look at the strategies adopted, a sample of in-house and off-campus students completed between one and four diaries each and attended a follow-up group discussion in return for fee. Even with this inducement there were problems in recruiting a sample. Whilst few, if any, students admitted that they would have taken part in the study without the fee there was also a feeling that the fee initially implied that there was a lot of work involved in completing the diaries. The target sample was primarily first year students as, it is assumed, they have fewer pre-conceptions about academic library services, but it was difficult to contact these students at the beginning of term. Initially there was a desire to keep the study separate from the department in which the students were studying but an insufficient response was received to personalised letters sent to students at their home addresses. More interest was generated following personal appearances at the beginning of lectures by the researcher to promote the survey work. This approach must have emphasised the implicit approval of the study by the teaching staff and it also meant that the samples were self- 
selected. The timescale allowed for setting up this work did not allow for pools of volunteers to be established at the different academic institutions from which matching groups of respondents could be compiled, but efforts were made to recruit evenly sized groups on the different courses. The chief difficulty was the time and administration involved in having to channel communications with the students via course tutors who may only see the students on a weekly basis.

There were also problems with some courses, for example, Engineering and Leisure, in identifying pieces of work with a substantial library element for which comparable groups of students could complete diaries. The researcher liaised with a member of teaching staff in each department to identify suitable assignments, though for Engineering and Health the sample of assignments chosen were set by more than one tutor. For some courses, such as English, only one or two pieces of assessed work were set over the whole year. In others, such as Health and Business, due to the rapidly increased class size, there is a much greater reliance on case-study work and studentselected topics. This had an impact on the survey work in that it will not always be possible to compare like with like and yet this very situation has arisen because of the problems in providing a library service for large numbers of students studying the same topic. Nevertheless, focusing on particular assignments overcomes a common weakness of diary work by clearly indicating what should be included in the diary. Practically, it allows a fairly intensive examination of the issues; quantitatively, it is possible to make realistic comparisons across groups of students; and qualitatively it enables the findings to be placed within the study context for each student.

The design and production of the actual diaries was limited by finance and by the fact that the diaries were to be used by different groups of students at different institutions. Physical design and layout of diaries is an interesting issue and the researcher drew from recent work at Leeds Metropolitan University ${ }^{(3)}$ which has examined some of the issues surrounding diary design. For example, although diaries allow users' actions and reactions to events to be recorded at the time of occurrence, essentially people are not used to keeping a record of their activities. Without a predetermined structure for recording, the data are likely to be somewhat undigested and difficult to analyse; however the more structured the diary then the more limits are placed on possible responses and insights.

In practice the diaries were quick to complete and could be carried around as students were asked to complete their diaries as they do the piece of work. Each five page A4 booklet contained a brief introduction to the study, a profile asking for basic information about the respondent, three copies of the 'diary of activities' page, plus some basic guidelines for completing the diary and an example of a completed diary page. A sample page is provided at the end of this article. As well as collecting chronological data on the time and place of work the main interest of the diary forms was in finding out about materials used and any, not just academic, library services/facilities used for the assignment. Students ticked coded boxes to indicate what was used and also gave free comments in the second half of the page by referring to the relevant line number. Each diary page is selfcontained and respondents complete as many or as few lines as necessary to record their activities. All students involved in the survey attended a briefing meeting when the first diaries were distributed.

\section{What sort of data did the diaries produce?}

This section presents examples of the data illustrating actual library use by one sample of Health Studies students, as recorded in the diaries. The abbreviations used on the graphs are expanded at the end of the article. 
At the beginning of the diary survey the two samples of BA Health Studies students were about equal in number. The drop-out rate at the off-campus site reduced the original sample size from twelve to seven students who went on to take part in the group discussion. One student left the course. The original sample at the in-house site numbered fifteen students.

Regarding where students are working, a straightforward analysis of the times and locations given in the student diaries indicated various findings.

- Off-campus students spent a lot of time working from home. For example, for over two-thirds of the assignments ( 20 out of 28 ) the students were spending at least two-thirds of their time working from home. On four occasions the students worked entirely from home.

- Eight assignments, accounting for over a quarter of the assignments set, were completed where the student did not appear to use any library at all.

- Four out of ten assignments (19 out 47) submitted by in-house students had been completed without using any library. Sixteen of these assignments had been completed entirely at home.

- In-house students used the university library for just over half (28 out of 47) of the assignments. In only six of these cases did the time spent in the library account for over half of the time spent on the assignment. In contrast library usage for a third of the individual assignments accounted for less than, or at most, a quarter of the total amount of time spent on the assignment.

These points are interesting certainly but the diaries offer little explanation as to why the students worked where they did for the time that they did.

The charts below show the proportions of students who made use of various library materials and services, so that it is possible to visually compare the actions of the in-house and off-campus samples.

Figure A Health Studies

Use of library materials by off-campus and in-house students for four assignments

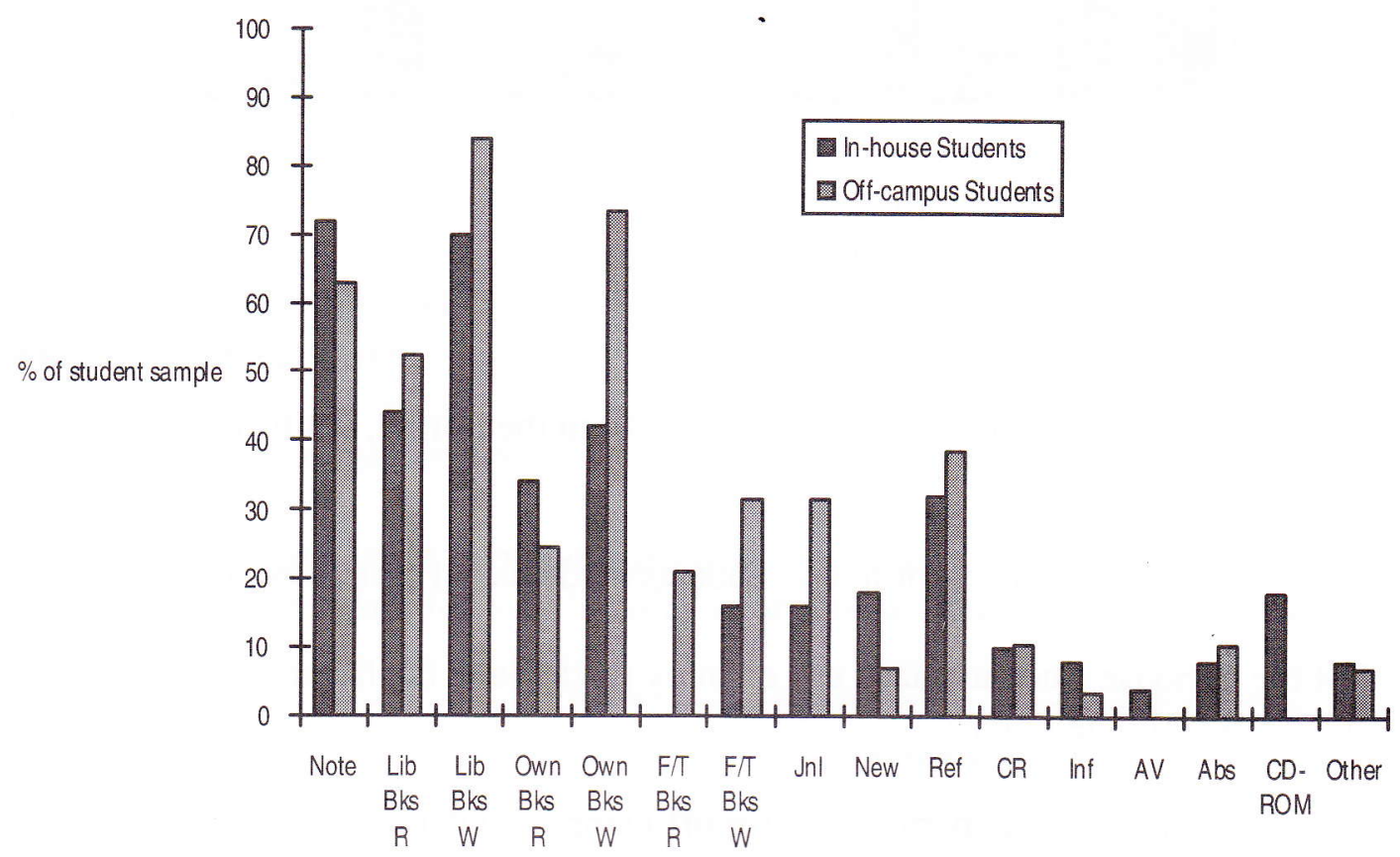


Tentative conclusions can be drawn regarding the use of library materials, for example,

- in-house students made most use of wider reading library books and their own notes and both to the same extent.

- off-campus students tended to make correspondingly slightly more use of wider reading library books and slightly less use of their own notes.

- off-campus students made almost twice as much use of their own wider reading books than inhouse students.

- furthermore off-campus students were the only students to make use of recommended books belonging to a friend or tutor and were also much more likely to make use of wider reading books belonging to a friend or tutor.

Figure B Health Studies

Use of library services by off-campus and in-house students for four assignments.

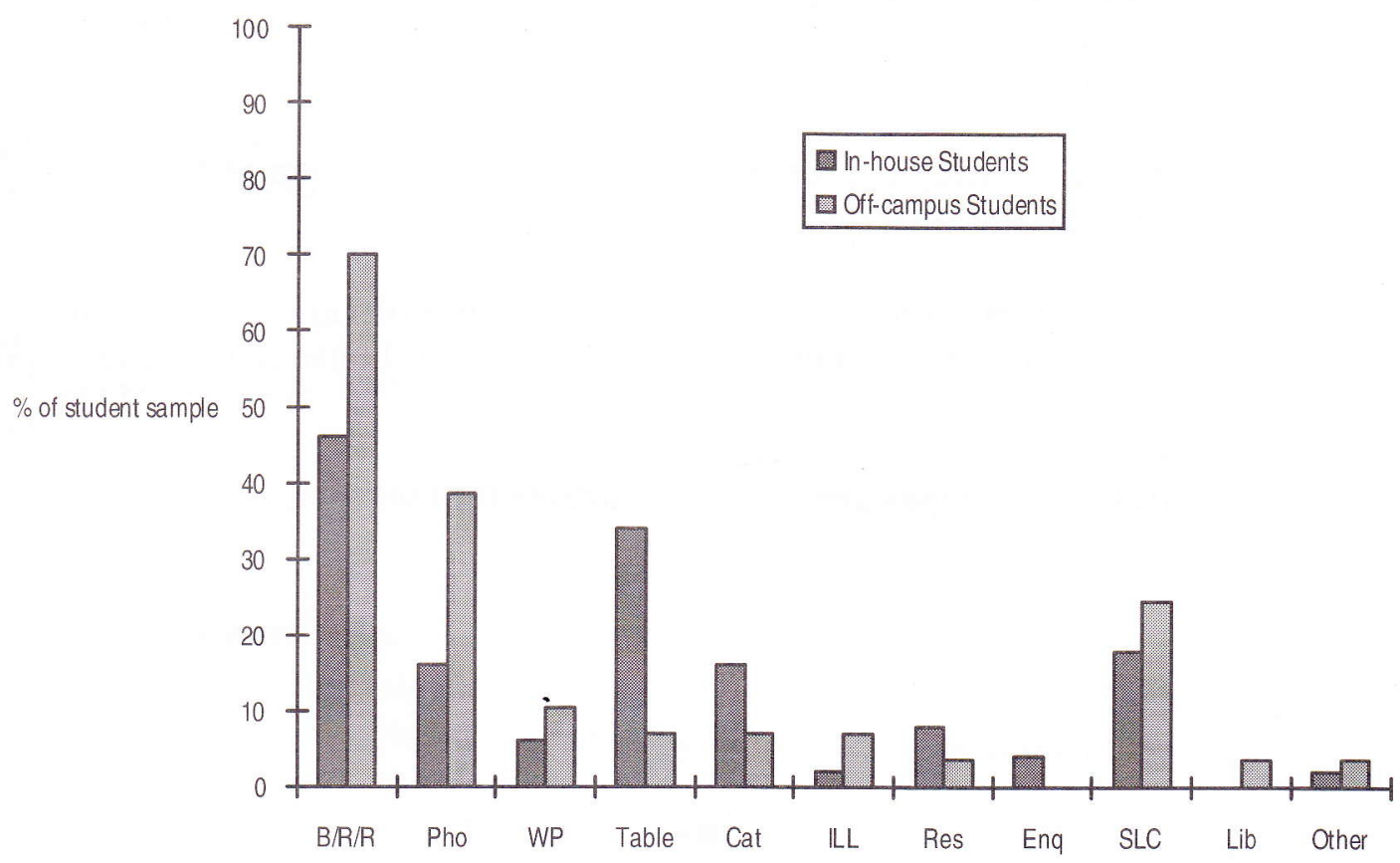

Again, some tentative conclusions can be put forward.

- Less than half of the in-house sample borrowed material from the library, whilst almost $70 \%$ of the off-campus group did.

- Twice as many off-campus students as in-house students made use of a photocopier.

- About a third of the in-house students made use of study facilities in the library. Very few offcampus students worked in the library.

- There was low use of the catalogue, particularly for off-campus students. 
So it is possible to make general statements about library use. In some cases comments made in the diaries threw some light on the situation. For example, regarding photocopying one student helpfully explained:

I used the photocopier a lot but not the one belonging to the library which charges $10 p$ a copy. There is an enterprising corner shop very close to the college doing photocopies at $4 p$ a copy.

Others described the problems of getting hold of the relevant books in time:

I made two reservations for books which I require for this assignment. However the books are not due back until two days before the deadline for the assignment. It is also unlikely that I am the only person to have placed a reservation. If this is the case I will have to complete the assignment without the aid of the information I require.

But generally it was pot luck for the researcher as to whether the student included any enlightening comments. Consequently it was essential to have some follow-up activity and this took the form of focus group discussions. By using the diaries as an aide-memoire the students were encouraged to reconstruct their way of tackling assignments and to describe the impact of any problems encountered and the strategies adopted to complete the work.

For example, regarding the off-campus students, it is now possible to elucidate on their apparently low use of the library for studying. Little use was made of the college library as a study place because of the noise from "younger students" and staff time was seen to be "wasted on trying to keep the library quiet." The typical approach then was to work at home:

I do all of mine at home. I've recently been doing the bulk of the research in the library purely because I'm not studying, I'm just looking for the work. I get the books here, photocopy them, and then go home.

Similarly, during the discussion there was a stream of complaints about the photocopying facilities in the college which confirmed the comments written in one of the diaries: "it's hardly ever working ... and you can't use both sides of the paper ... and it won't take new 10ps ..." So what happened in practice was that students would use "a little place across the road" where copies were only $4 \mathrm{p}$ a sheet instead of $10 \mathrm{p}$; or alternatively one student would "usually borrow the books and photocopy them for everyone else."

During the discussion too it became apparent that although a library guide had been produced for Health Studies the students still had problems in finding books in the library. Part of the problem was due to the nature of Health Studies stock in that it covers many subject areas; but the students had also been baffled by what they felt was inconsistent cataloguing:

Even now, you go over there for books in sociology and they're under psychology.

We've all found that things are actually under strange categories which we wouldn't think about looking for - we've all found things by accident - but it has got easier.

They're all over the place. We found a health promotion book filed under engineering, I couldn't believe it, what that had to do with engineering? The mechanics of health I suppose! 
Consequently they made little use of the catalogue, preferring to browse the shelves. In fact most of the students in this group preferred to use wider reading, rather than recommended books. They explained that this was because they could not find the books, and when they did, they did not think they were very good:

You can't find recommended books. We're given a reference sheet by the tutor to research but you are very lucky to get one off the page... in the end I never even looked at the references, I just look on the shelves.

When I have found a recommended book it's been of little use. They're very narrow.

The wider reading is much better. I never look at the reference sheet now, I just look for my own.

This group were also generally heavy book buyers and certainly enthusiastic about buying books, although they complained bitterly that they had wasted money on buying the wrong edition of a set text book for psychology. They talked about where they got books and other resources for the course from.

It's the obscure books that you've bought that have been really useful. The ones you pick up by chance that are most useful. I've got one that's excellent, and I use it for everything as a basic, and it's not in any of the libraries so no one else is using it.

We're always sending off for things like $B B C$ books ... it's small amounts of money and it's bang up to date.

I picked up a really good book in a second-hand book shop in Manchester and that's been great for a lot of these essays.

And there's so much on television as well these days if you want something really up to date ... and a lot of them have a book at the end. I found the OU good - I watch that if you know beforehand what's coming on you can set your tape or stay up and watch it...

But buying could not resolve all of the problems because "it's such a broad subject and you need so many books that you just couldn't afford to buy them all anyway."

Using the combination of diaries and focus group discussions provided a very rich and vivid picture of student use of libraries and certainly provided a much truer description of library use than had only one method, either diaries or focus groups, been used. Indeed, had diaries been the sole method for recording the student experience then the 'results' would have produced more questions than answers. The follow-up meetings, which took place when all of the diaries had been returned and analysed, assisted in determining the typicality of the diary record and in providing reasons for actions. These focus group discussions were fairly informal in nature but they all took the same approach in using the diaries as an aide-memoire. The students could be prompted to recall specific examples to support the rather general statements that can arise in group discussions. Thus the information recorded in the diaries provided both an end-product, that is a record of actions taken, and a starting point for considering students' information strategies. In conclusion, in this study the diaries proved to be a useful method of data collection, and seem to have allowed reasonably accurate records to be collected over a fair time-span (up to six months with some groups). However, as with all data, it must be handled with care. 
Table 1 Abbreviations referring to use of library materials

\begin{tabular}{|lllll|}
\hline Notes & $\begin{array}{l}\text { Using own notes e.g. lecture notes, notes } \\
\text { made previously from books etc. }\end{array}$ & Jnl & Journals \\
Lib Bks R & Library Books...on reading list / recommended & Rew & Newspapers \\
Lib Bks W & Library Books...other wider reading & Reference e.g. dictionaries, directories \\
Own Bks R & Own Books...on reading list / recommended & CR & Course reader e.g. photocopies from tutor \\
Own Bks W & Own Books...other wider reading & Information files \\
F/T Bks R & $\begin{array}{l}\text { Friend's/Tutor's Books - on reading list / } \\
\text { recommended }\end{array}$ & AbsPrinted abstracts/indexes \\
F/T Bks W & Friend's/Tutor's Books...other wider reading & CD & CD-ROM \\
\hline
\end{tabular}

Table 2 Abbreviations referring to use of library services

\begin{tabular}{|c|c|c|c|}
\hline $\mathrm{B} / \mathrm{R} / \mathrm{R}$ & Borrowing/returning/renewal & ILL & Inter-library loan service \\
\hline Pho & Photocopier & Res & Reservations \\
\hline WP & $\begin{array}{l}\text { Word-Processing facilities in the } \\
\text { library }\end{array}$ & Enq & $\begin{array}{l}\text { Enquiries relating to this } \\
\text { assignment }\end{array}$ \\
\hline Tables & $\begin{array}{l}\text { Study Tables - private study / } \\
\text { group work }\end{array}$ & SLC & Short Loan Collection \\
\hline Cat & Library catalogue & Lib & Library guides/publications \\
\hline
\end{tabular}

\section{References}

1 See Goodall, D. "Use of diaries in library and information research" Library and Information Research News Spring 1994, vol. 18, no.59, 17-21, for a detailed discussion of this methodology.

2 Hoy, C. and Hale, M. "A comparison of references cited by on-campus and off-campus graduate Library Sciences students"The Off-Campus Library Services Conference, Albuqueque. New Mexico, USA, October 30 - November 1, 1991 Proceedings Mt. Pleasant, Michigan, USA: Central Michigan University Press, 1991, 123-127.

3 The effectiveness of diaries as a method of determining how students spend their time. Leeds Metropolitan University, 1993 Internal document kindly made available by Mrs K. Crump

\section{Analysis of the impact of research information on practitioners}

DOROTHY WILLIAMS, KAY WILSON and MICHAEL MCCONNELL

School of Information and Media

The Robert Gordon University

\section{Introduction}

Research findings, if they are to fulfil their purpose, must be perceived as valuable and worth accessing. The role of research is to change the status quo, therefore findings need to be absorbed 